\title{
Is El NiÑo BECOMING More Common?
}

\author{
By David B. Enfield
}

E L Niño is an anomalous warming of the eastern tropical Pacific Ocean that occurs at 2-10 year intervals and is frequently associated with far-reaching climatic and economic impacts around the world. Intensive research following the disastrous 1982-83 event has led to a much greater understanding of the phenomenon and some recent successes in prediction using new, coupled ocean-atmosphere numerical models. The most widely supported hypothesis at present is that El Niño occurs as an internal oscillation of the tropical Pacific Ocean-atmosphere system. While this is not universally adhered to, all agree on one fundamental aspect: that the El Niño condition only evolves after an unstable cycle of positive feedbacks between ocean and atmosphere is established along the equator in the central Pacific.

Along the coast of Peru and in the equatorial region surrounding the Galapagos Islands, the southeasterly trade winds normally pump cool, nutrient rich water from below the shallow thermocline into the surface layer. During El Niño, the winds in the western and central Pacific decrease or reverse, which generates eastward propagating Kelvin waves and leads to the depression of the thermocline and thickening of the upper ocean warm layer in the the eastern Pacific. Although the winds in the east are little changed and continue to favor the upwelling in the physical sense. the cooler. nutrient-rich water is deeper and therefore less available to be upwelled. The sunlit surface water becomes warmer and depleted of life-sustaining nutrients. The higher sea surface temperature (SST) pumps excess latent heat of evaporation into the atmosphere, further weakening the trade winds farther west and thus contributing to the growth of the instability. As the surface sterility persists and increases. microscopic algae become much less abundant and the biomass and distribution of other forms of marine life are drastically altered.

Vacillating time sequences of El Niño cycles have been simulated in coupled ocean-atmosphere models with some success (Zebiak and Cane, 1987: Schopf and Suarez, 1988). The underlying physical proc-

David B. Enfield, NOAA Atlantic Oceanographic and Meteorological Laburatorv. 4301 Rickenhacker Causeway. Miami. FL 33179 . esses interact and evolve to produce a succession of bifurcations or switches between the El Niño and a non-El Niño state that closely resemble what we see in nature (Fig. 1). Although for a given set of model parameters and initial conditions the time evolution will appear to have stable statistics of properties, such as the intensity of anomalies and the interval between events, the process never repeats itself exactly. In fact, under even the smallest of changes in the initial conditions, the models will evolve differently during successive computer runs (Zebiak. personal communication). With significant, though realistic, changes in the parameter settings (Fig. 1. p. 24) the statistics themselves may become quite different, e.g., with different amplitudes, longer intervals between events, and so forth.

If the statistics of natural El Niño variability are as sensitive to the background climate as the model evolutions are to their parameter settings, then $\mathrm{El}$ Niño cycles may not have always been as ubiquitous or intense as they are today (or. conversely, more so). The sensitivity issue is critical in the present stage of research, and could have important implications for environmental variability in the next century, when it is anticipated that the Earth may be several degrees warmer.

A number of scientists in non-oceanographic disciplines (paleontologists, glaciologists, geologists, etc.) are presently addressing this question by studying proxy indicators of ElNiño in the ancient record (ELNAR). On time scales of many thousands of years (glacial epochs), we know that the climate was indeed quite different. Studies of sediments, molluscan assemblages and other evidence along the Peru coast indicate that El Niño-like events (e.g.. massive coastal flooding. faunal changes, etc.) probably occurred throughout the Pleistocene, or roughly the last 30,000 years. There is considerable disagreement. however, as to how common such occurrences were and whether or not they were due to ancient $\mathrm{El}$ Niño episodes (DeVries. 1987). On the time scale of millennia. such proxy records presently cannot resolve unequivocally the occurrence of widespread ocean warmings with sufficient (annual) time resolution.

The prospects appear better for ELNAR investi-

\section{El Niño cycles may}

not have always been

as ubiquitous or

intense as they

are today. 


\section{During El Niño}

years the ice cap in

southern Peru receives

less precipitation

and is warmer than in

non-El Niño years gations based on core sections taken from the Quelccaya Ice Cap (Peruvian Andes) (Thompson et al., 1984) and recently-living corals in the Galapagos Islands (Shen et al., 1987). In both cases, strong seasonal processes produce annual layering that allows researchers to establish chronologies dating back 500 years or more, and with characteristics that reflect climate-related physical and/or chemical changes in the environment. Moreover, interpretation of the core samples can be extended to the present and compared to El Niño/Southern Oscillation (ENSO) indices based on modern measurements, thus establishing their credibility. Finally, the 500 year time scale includes the so-called "Little Ice Age" (LIA), a period of globally lower temperatures that extended roughly from A.D. 1500 to 1850 . Thus, these proxy indices can potentially tell us something about both the El Niño variability and the background climate in which it is set.

The ice core method detects interannual changes in the vearly snow accumulation (precipitation) and oxygen isotope ratio (depositional temperature) of the ice cap. The coral samples show similar changes in the concentration ratio of cadmium (a micronutrient in sea water) to calcium $(\mathrm{Cd} / \mathrm{Ca})$. The $\mathrm{Cd} / \mathrm{Ca}$ ratio is proportional to the availability of nutrients - and by inference, colder water - to the upwelling process along the equator. In both cases there is a striking correlation between the proxy records and the ENSO indices over the last 2-3 decades (Fig. 2) (Shen et al., 1987). During El Niño years the ice cap in southern Peru receives less precipitation and is warmer than in non-El Niño years, while fewer nutrients are assimilated in coral growth at the Galapagos.

Opinions about El Niño variability prior to modern records are divided. Shen and co-workers (unpublished manuscript) have recently analyzed a much longer coral record from the Galapagos, dating from A.D. 1600 . A remarkable change took place around the mid-19th century, when the $\mathrm{Cd} / \mathrm{Ca}$ proxy background levels of available nutrients became significantly lower than they had been during the LIA. Because of the inverse correlation between nutrients and SST, the authors infer from this that the waters surrounding the Galapagos may have been generally cooler during the LIA, consistent with the cooler conditions also noted in the ice cap data and other proxy studies. They conclude that Galapagos waters during the LIA were largely immune to catastrophic nutrient limitation of the kind associated with modern El Niño events, and that "the concept of El Niño as a persistent feature influencing the eastern tropical Pacific during the past millennium may have to be reexamined."

Contrary indications come from a recent study by Michaelsen (1989) of tree-ring records from arid-site conifers in southwestern North America. He finds that ENSO variability (as inferred by regression on large scale Indo-Pacific indices) has occurred over the last 400 years with amplitude and frequency statistics very similar to those of the 20 th century.
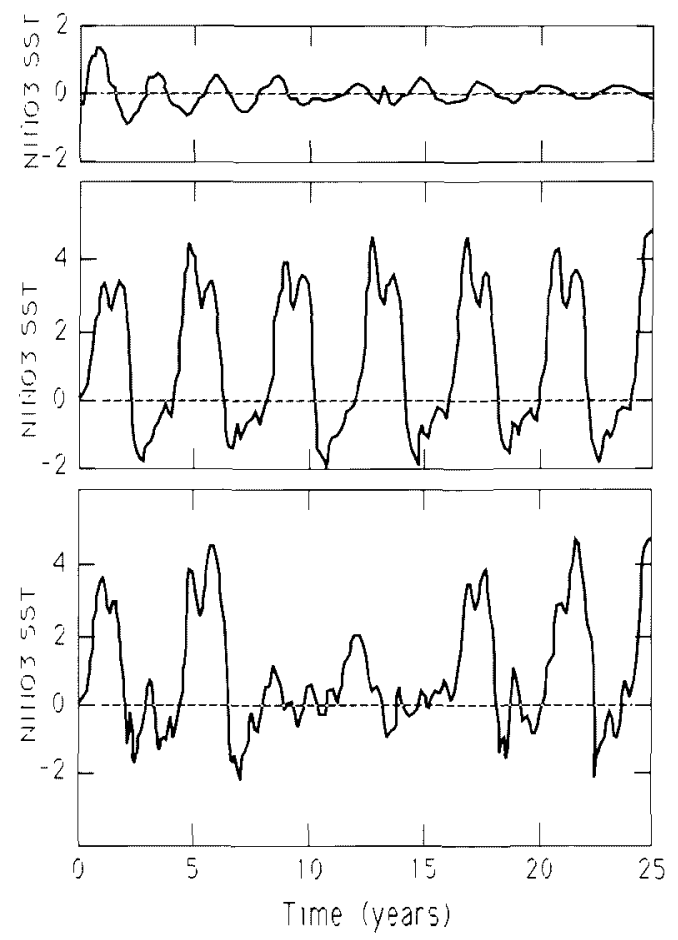

Fig. 1. 25-year computer simulatroms of sea surfiace temperature in the east-central equatoflal Pacific, by the aripled oceanatmosphere model of Zebiah and Cane l losi) Each ease is a varian of a "standard" run using henchmark model parameters, In wheh one of the parameter settmes has been changed. In the

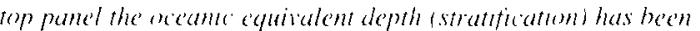

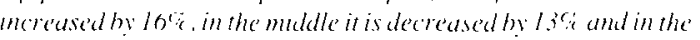

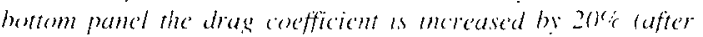
Zebluk and Canc, 1987).

This would suggest that El Niño variability is remarkably impervious to significant changes in the background climate. There is an important caveat to comparisons between the ELNAR studies, however: the coral and ice cap results are perhaps more likely to represent the regional El Niño, per se. while treerings probably reflect the larger scale "teleconnections" associated with the broader ENSO interaction. We are cautioned by Deser and Wallace (1987) that there is not a unique correspondence between occurrences of El Niño and ENSO. Thus, for example. equatorial ocean warmings have occurred. possibly associated with teleconnections to midlatitude weather patterns, that have not registered as significant El Niñoevents along the South American coast: the reverse misfits have also been noted.

Fortunately, Quinn etal. (1987; henceforth, QNA) have constructed a history of strong El Niño events beginning with the arrival of Francisco Pizarro in Peru in 1525. To do this, they supplemented scientific data on modern occurrences (1891-1983) with information judiciously ferreted from colonial archives, privateer logs and the early accounts of the post-conquest era by Spanish and Peruvian historians. Centuries ago, El Niño was not known as it is today (see the sidebar), but its occurrence can be inferred from the severe rainfall and flooding episodes experienced by the colonists in the otherwise 


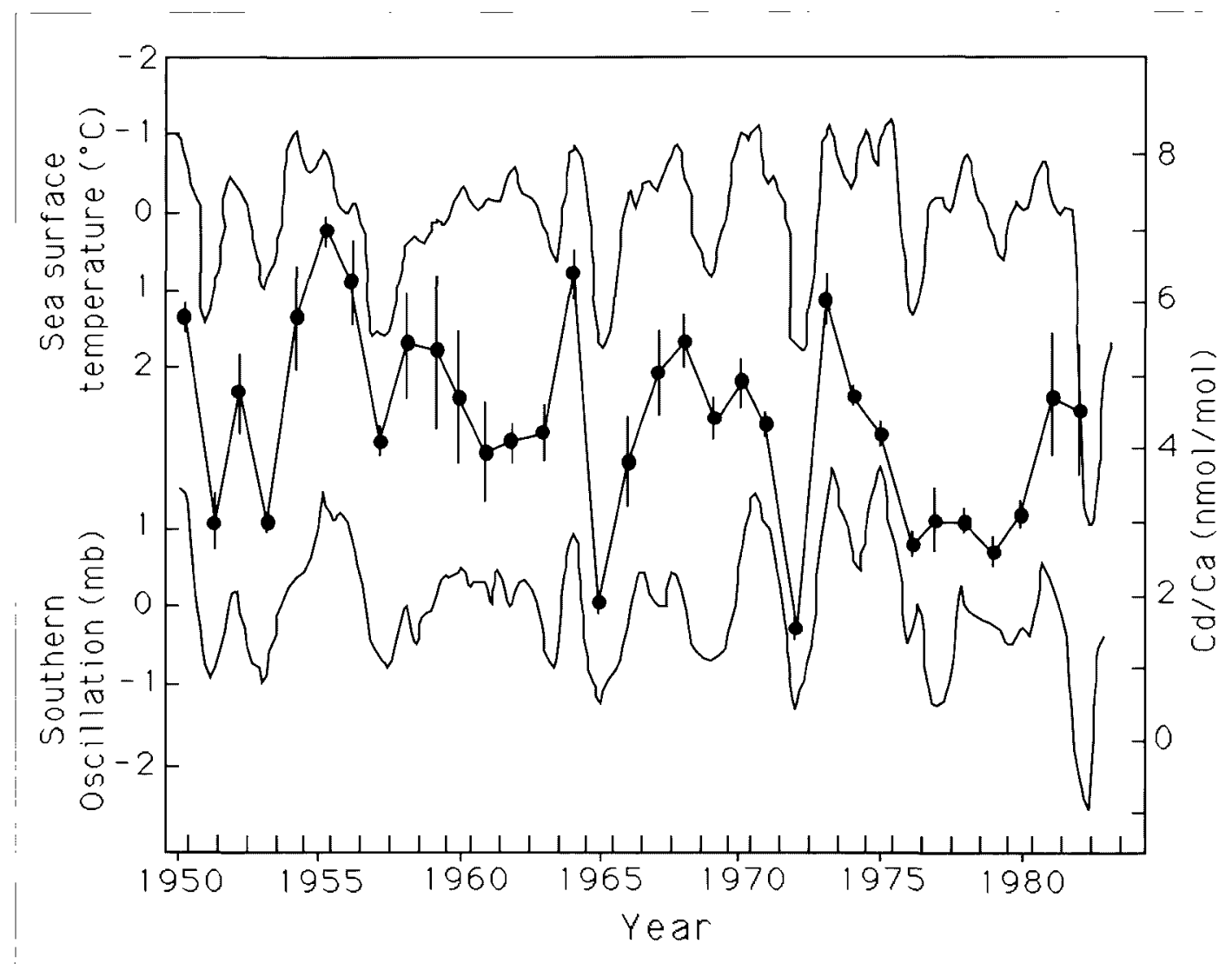

Fig. 2. Reconstructed histery of $\mathrm{Cd} / \mathrm{Ca}$ (muddle (whe) in a section of massive cord (Pavona clavus) from the San Cristobal Island (Galapagos). ampared a ganst the sea sarface tempera-

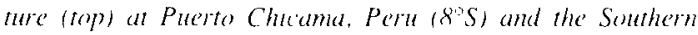

extremely dry, desert environment of northern Peru. as well as from their recorded impact on farming and commerce.

Much of the source material for the QNA study makes for fascinating perusal. The first recorded case (though not called "El Niño" at the time) was in 1525, when the conquistadores marched into their new empire amid clear signs of copious desert rainfall and agricultural fertility. According to Murphy (1926),

... it has been suggested that the march which Pizarro made through Piura, while on his triumphal journey toward Cuzco. was possible only because he chanced upon the desert shores during one of the rare años de abundamia. or years of abundant water and vegetation.

Another account, cited by Eguiguren (1894) in reference to the disaster of 1728 , relates how the Piura River became a raging torrent, carrying away many unfortunate victims. The survivors were mainly women - they were saved by their hoop-skirts. which trapped air and kept them afloat.

The QNA classification recognizes four basic categories of El Niño intensity: weak to moderate $(\mathrm{W} / \mathrm{M})$, moderate $(\mathrm{M})$, strong $(\mathrm{S})$ and very strong (VS), and identifies borderline cases as $\mathrm{M}+$ and $\mathrm{S}+$. The well known episodes since 1950 are classed as:
Oscillation index (SOl, bottem). The SOl is defined here as the difference in anomalous atmospheric pressure botween Tuht and Darwin. Australad. Note that the temperature scale has be'n imerfed (after Shen et al., 1987).

$195 \mathrm{I}(\mathrm{W} / \mathrm{M}), 1953(\mathrm{M}+), 1957-58(\mathrm{~S}), 1965(\mathrm{M}+)$. 1972-73(S), $1976(\mathrm{M}), 1982-83(\mathrm{VS})$ and $1987(\mathrm{M})$. $\mathrm{W} / \mathrm{M} . \mathrm{M}$ and $\mathrm{M}+$ episodes are only reported for the 19th and 20th centuries, because the threshold for acceptable evidence is low and the older sources less reliable. The stronger cases ( $\mathrm{S}, \mathrm{S}+$, and VS) are traced back to 1525 .

One should perhaps give more credence to the identification of an EI Niño as having occurred than to its specific intensity. Much of the QNA evidence is based on flooding episodes in the seasonally dry, low-runoff rivers of northern Peru, which is due as much to mountain rainfall as to precipitation on the desert itself. Unlike the altiplano in the Andes of southern Peru, where El Niño is associated with drought, it appears that the western slopes of the Andes in northern Peru do receive more rain during El Niño (Horel and Cornejo-Garrido. 1986), hence stream flow remains a valid indicator. However, although modern stream flow measurements correlate significantly with EI Niño episodes, that correlation is not so high as to permit a rigorous intensity scale based on that variable alone. The QNA study uses other, subjective indicators, but it is nevertheless easier to say that a "strong" El Niño occurred (i.e., is detectable from anecdotal sources over long time periods) than to be specific about its intensity. This makes the onset interval statistics more useful.
The survivors were mainly women - they were saved by their hoop-skirts, which trapped air and kept them afloat. 


\section{"El Niño:” How Has The Name Evolved?}

A

$\mathrm{N}$ episode of very severe desert rainfall and flooding occurred in the austral summer (January-April) of 1891 in the Sechura desert of northern Peru, and an intense nearshore countercurrent was observed to carry unusually warm water and tropical debris from the Guayas estuary in Ecuador far south of its origin to Pacasmayo $\left(7^{\circ} \mathrm{S}\right)$ on the north-central Peru coast (Carranza, 1891). Peruvian geographers. who that very year had inaugurated their own professional journal, the Boletin de la Sociedad Geografica de Lima, took note of the event and were intensely interested in the implications of the cool, northward Humboldt Current and its nemesis (the countercurrent) for the coastal climate of their country.

At the close of the 19th century, "El Niño" was not a popularized term in general use. Carranza"s (1891) report refers only to a southward setting countercurrent and makes no mention of "El Niño." It was only a year later that Carrillo (1892), a ship's captain familiar with the marine folklore of the region, made the connection. Referring to Carranza's observations, he tells us:

The Paiteño mariners who frequently sail close to shore in small boats, north and south of Paita

[one of the oldest fishing ports in Peru, situated near $5^{\circ} \mathrm{S}$ ], know this current and call it corriente del

Niño, undoubtedly because it becomes most visible and apparent after Christmas. ... We are assured

by illustriate mariners that this countercurrent from the Gulf of Guayaquil appears every year during

the [austral] summer months; but that, in general, it is very weak, such that only the most practiced

notice it.

No historical references can be found as to when the Paiteños first christened the current. However, the earliest logged observation of the southward setting flow was in 1822 by M. Lartigue, aboard the French frigate La Clorinde. Later, Captains of naval and commercial vessels that regularly transited the shipping route along the northern coast became familiar with the countercurrent, because it would advance or delay their arrival times depending on the direction of travel. Their sailing logs also mention a lack of any regularity in the appearance of the countercurrent, or of any reliable correlation with the occurrence of winds from the north (Carrillo, 1892).

From Carrillo's comments, it seems that EI Niño referred only to a nearshore countercurrent, that it was an annual summer event, albeit weak and sporadic, and that it was known to be stronger and more extensive in certain years. On the other hand, residents of Piura, situated inland of Paita on the Sechura Plateau, were only too familiar with the occasional year that would bring unusual rains and flooding, yet none of their early accounts associate the climatic aberrations with the countercurrent or the name "El Niño." Beginning with the 1891 event, however, Peruvian scientists began to draw a connection between the more intense appearances of the countercurrent and the climatic anomalies, noting the presumed effect of the warmer surface water on regional evaporation and precipitation patterns. After renowned foreign scientists (Murphy, 1926; Schott, 1931) took note of the severe anomaly of 1925 and associated it with the proverbial countercurrent, the notion of "El Niño" as an anomalous climatic event began to take hold.

Schweigger (1945), a keen observer and frequent traveler to the north coast, objected to the new usage. He used his coastal observations in an effort to show that the annual countercurrent was different from the anomalous event - which he preferred to call the Equatorial Countercurrent - and argued that the term "El Niño" should retain its original (annual) meaning. His advice went unheeded. Following the strong episode of 1957-58, the anomalous connotation of the term was more firmly entrenched than ever, propagated through the world's oceanographic literature. Beginning with the work of Bjerknes (1961), scientists began to realize that the anomalous EI Niño is associated with basinwide perturbations of the tropical ocean and atmosphere. The notion of El Niño as an annual, uniquely Peruvian phenomenon has now been largely usurped by the much wider global and interannual connotation that we know today.

As with other physical phenomena that involve recurrence interval as a stochastic variable (e.g.. surface wind waves), the onset intervals for the strong events fit a Rayleigh distribution with a high degree of confidence ( $R^{2}=0.98$, rmse $=0.16$ years). Hence, the mean interval a bit less than ten years, or 47 QNA events in 4.6 centuries - is not the most frequent for the skewed distribution. The most common interval between strong El Niño events is seven years, which helps to understand some of the (discredited) historical attempts to establish this figure as a periodic recurrence rate. It is fairly rare $(-5 \%)$ for strong events to occur at intervals of less than three years or more than 17 years. Naturally, if we count the $\mathrm{W} / \mathrm{M}, \mathrm{M}$ and $\mathrm{M}+$ events as well, the recurrence rate is higher (smaller intervals), but that is not so interesting here because the low intensity cases are more difficult to detect and classify, and are probably not as significant in terms of their large 


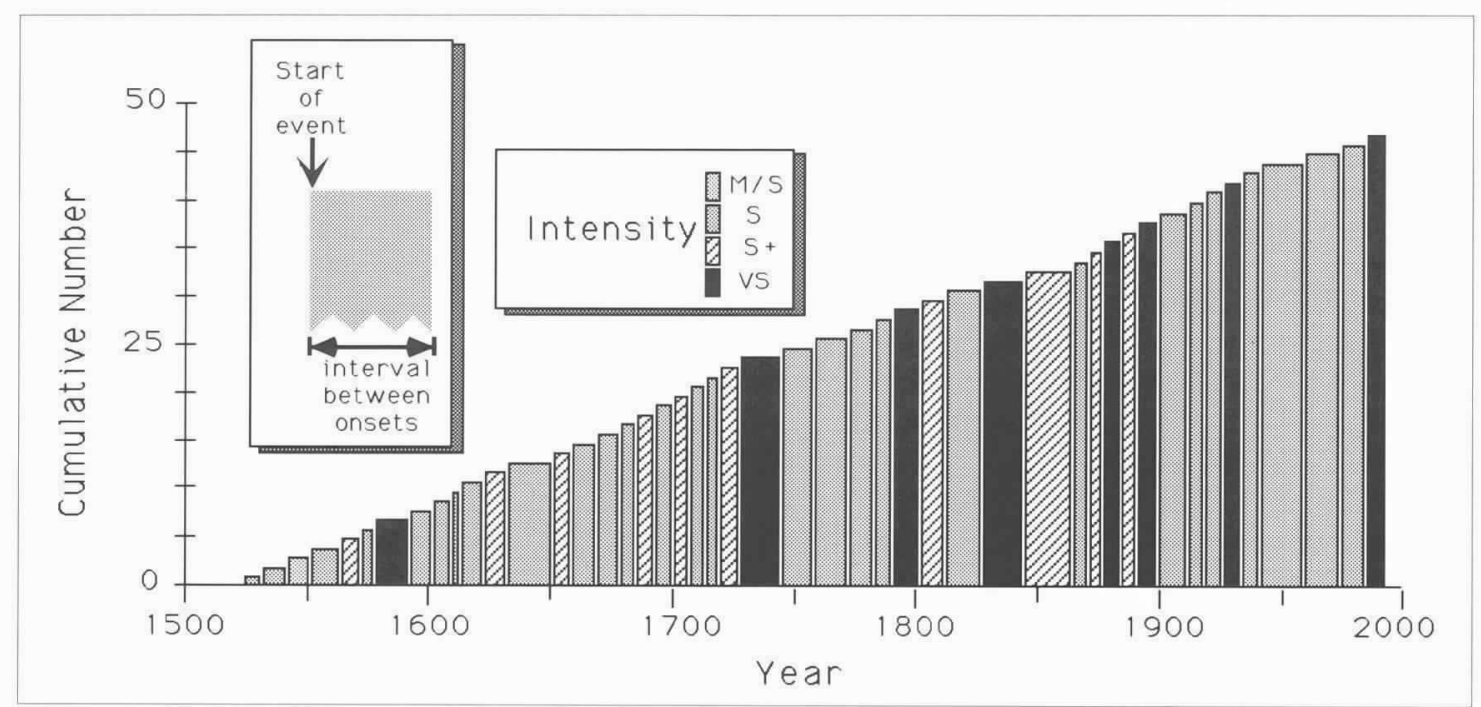

Figure 3. Occurrences of El Niño since records began in Peru, based on the chronology of Quinn et al. (1987). The width of each bar represents the time interval between two successive onsets of

scale climatic impacts.

The results for strong events (M/S, S, S+ and VS) are summarized graphically as a cumulative frequency chart (Fig. 3). If El Niño were perfectly periodic (uniform interval between onsets), the "staircase" would follow a straight line toward the upper right. What we see, in fact, is a stochastic time distribution of intervals and intensities. Curiously, there appears to be a quasi-centennial cycle between times (at the ends of centuries) when El Niño is more intense and frequent, and those (near mid-century) when the opposite is true. This same amplitude/ frequency modulation is observed in the tree-ring data by Michaelsen (1989). Note that the strongest episodes do not occur after long periods of non-El Niño conditions. This is interesting, because one might expect the accumulation of warm upper layer water in the western Pacific (which is "released" eastward during ENSO) to be greater following a long period of easterly winds along the equator (the non-El Niño portion of the ENSO cycle). Were that so, the ensuing El Niño might also be stronger, but this does not appear to be the case.

The most significant feature of Fig. 3, as it relates to climatic epochs, is that El Niño intensities and intervals seem no different now than they were when the Spanish records began. Of course, we are assuming (as QNA did) that the relation between precipitation/flooding and El Niño has not changed either. We could perhaps say with greater confidence that episodes of strong precipitation and runoff in northern Peru were probably no less frequent during the LIA than they are now.

The onset-interval statistics from the QNA study appear less consistent with the recent indications from Galapagos corals than with the results of the Michaelsen (1989) tree-ring analysis. However, the 400 year coral chronology presently lacks the temporal resolution required to resolve individual El Niño events, as in the modern (trimonthly) record of Fig.
El Niño and the height is the cumulative number of events since 1525. Intensities (defined in the text) are shade-coded according to the legend.

2, p. 25; hence it is difficult to say with certainty whether El Niño-related decreases in $\mathrm{Cd} / \mathrm{Ca}$ occurred in the LIA, superimposed on a background of more productive water. Should closer scrutiny of the $\mathrm{Cd} / \mathrm{Ca}$ data fail to reveal El Niño variability in the LIA, it still does not necessarily mean that the coral record is inconsistent with the anecdotal (QNA) chronology. One can imagine a stronger trade wind regime (under a colder climate) that would produce a greater zonal tilt in the equatorial thermocline, and a generally shallower mixed layer than at present. This implies a greater background nutrient flux, which is probably a nonlinear function of forcing, as is the diabatic transfer of heat across the thermocline. It would not necessarily preclude ENSO cycles or diminish their frequency from a physical point of view, but it might decrease the contrast in nutrient levels between phases of an ENSO cycle, making El Niño less detectable by chemical means.

In conclusion: Both coupled ocean-atmosphere models and coral records over the last half-millennium suggest the possibility that the statistics of El Niño occurrences may be linked to the background climate. However, the evidence is still tenuous and inconsistencies have arisen between various studies. The low cadmium content in Galapagos corals prior to 1850 implies that growth limitation by nutrient availability was not a factor in the Little Ice Age, and that El Niño may have been significantly less ubiquitous than it is today. Tree-ring analysis, however, suggests that El Niño statistics are quite robust between the Little Ice Age and the present. In support of the latter study, the catalogued occurrences of El Niño (based on historical accounts in Peru) indicate that strong El Niño events were probably no less intense or frequent in the LIA than they are today. It appears likely that El Niño statistics are stationary within the parameter range of climate changes that have occurred within the last several centuries. We

[ PLEASE TURN TO PAGE 59] 
Raymond B. Montgomery (1910-1988)

Raymond B. Montgomery died on August 15. 1988 in Woods Hole, Massachusetts at the age of 78 . His contributions to the understanding of the structure and motion of both the ocean and atmosphere were manifold and fundamental. A student of Carl-Gustaf Rossby, Montgomery conducted research that spanned a broad range of topics and scales, from turbulent mixing and heat transfer, to air-sea interaction; from the topography of the ocean surface, to the distribution of water masses in the world ocean. His research will perhaps be remembered best for his development and application of the techniques of isanosteric analysis, and for the discovery, with Cromwell and Stroup, of the Equatorial Undercurrent in the Pacific Ocean. He also sailed as a student on the maiden voyage of the Atlantis.

A list of specific achievements, how-

\section{Konstantin N. Fedorov (1927-1988)}

Konstantin Nikolaevich Fedorov, born in 1927 in Leningrad, USSR, died suddenly in Moscow on September 21, 1988. K.N. Fedorov earned a Ph.D. in physical oceanography at the Institute of Oceanology in Moscow, under the supervision of Professor Vladimir Shtokman. One of Fedorov's earliest scientific papers dealt with laboratory modeling of wind-driven circulation. From 1963 until 1970. he served as Secretary of the Intergovernmental Oceanographic Commission (IOC) of the United Nations Educational. Scientific and Cultural Organization. During this period he co-authored a paper with Henry Stommel on finestructure in the ocean. Fedorov also w'rote scientific books on finestructure and oceanic fronts, and his most recent book, co-authored with his wife A.I. Ginzburg, is titled The Near Surface Layer of the Ocean (in Russian).

Many ocean scientists saw Konstantin recently at the Joint Oceanographic Assembly and the Scientific Committee on Oceanic Research (SCOR) General Meeting in Acapulco. It was his last meeting as a member of the SCOR Executive Committee, and this was recognized during a happy SCOR party at which Konstantin regaled attendees with anecdotes about the occa- ever, provides an inadequate measure of Montgomery's profound influence on a generation of colleagues and students. He had a keen instinct in identifying major mechanisms of important oceanic and atmospheric processes which needed explanation. As a teacher and critic, he gave freely of this insight to encourage others in important directions of research. His high standards in scholarship and in the conduct of research served as a beacon for those around him. His friendship, insight and encouragement will be missed: his inspiration and influence will endure.

He leaves his wife. Polly, and three daughters: Kate Leonard. of Atascadero, California: Mary Howard. of Reading. Massachusetts; and Eleanor Montgomery, of Baltimore, Maryland.

Contributed by William C. Boricont and Glenna Cannon.

sional humorous misunderstandings which can occur in international collaborative activities. Farewells were said with regrets, but with the expectation that our paths would cross again in the course of international marine science.

Konstantin served as President of SCOR from 1976 to 1980 and as Past-President since then. He also chaired Working Group 69 on Small-Scale Turbulence and Mixing in the Ocean; one of the decisions of the SCOR General Meeting was to disband this group, which had completed its tasks with the publication of the proceedings of the very successful 1987 Liege Colloquium on the same topic. A final report of WG 69 is to be published by SCOR in the near future.

Konstantin N. Fedorov will be sorely missed by all who knew him and appreciated his sincere efforts to facilitate cooperation among oceanographers from all countries, both in his personal capacity and as a member of SCOR and Secretary of the IOC. His numerous scientific papers and books will remain as a lasting tribute to his significant contribution to physical oceanography.

Contributed by Elizabeth Tidmarsh. Executive Serretary. SCOR, and Sergei Dikarev. Senior Visiting Scientist, Dept of Occanography, Dalhousie Unversity. Halifax. N.S. B3H H.II. Camada.
Is EL NIÑO

\section{BECOMING}

MORE COMMON?

[CONTINUED FROM PAGE 27 ]

can speculate that EI Niño variability will probably persist through the next century in similar fashion, regardless of the present global warming trend.

\section{References}

Bjerknes. J.. 1961: E] Niño study based based on analysis of ocean surface temperatures. $I n t e r . \mathrm{Am}$. Trop. Tuna Comm Bull . 5. 217-234.

Carranza, L., 1891: Contracorriente maritima observada en Payta y Pacasmayo. Bol. Sox. Geograf. Lima, 1, 344-345.

Carrillo. C.. 1892: Hidrografía oceánica. Bol. Soc. Geongr. Lima. 2. 72-110.

Deser.C. and J. M. Wallace. 1987: El Niño events and their relation to the Southern Oscillation: $1925-$ 1986, J. Geophys. Rex. 92. 14,189-14,196.

DeVries. T. J.. 1987: A review of geological evidence for ancient El Niño activity in Peru, J. Geophvs. Re's. 92, 14,471-14,479.

Eguiguren. V.. 1894: Las lluvias en Piura. Bol Sor. Geogr. Lima. 4. 241-158.

Horel, J. D. and A. G. Cornejo-Garrido, 1986: Convection along the coast of northern Peru during 1983: Spatial and temporal variation of clouds and rainfall, Mom. Wha. Re'1.. I/4, 2091-2105.

Michaelsen. J., 1989: Long-period fluctuations in E! Niño amplitude and frequency reconstructed from tree-rings, In: Intcrdisciplinary Aspects of Climate lariahility in the Pacific und Western Americas, D. H. Peterson, ed., Am. Geophys. Union Monograph Ser.. 48 (in press).

Murphy. R. C., 1926: Oceanic and climatic phenomena along the west coast of South America during 1925, Geogr. Rev., 16, 26-54.

Quinn. W. H., V. T. Neal and S. Antunez de Mayolo, 1987: El Niño occurrences over the past four and a half centuries, I Geophys. Res., 92, 14.44914.461 .

Schopf, P. S. and M. J. Suarez. 1988: Vacillations in a coupled ocean-atmosphere model. $J$. Atmos. Scr. 45, 549-566.

Schot1, G., 1984 (1931): The Peru (Humboldt) Current and its northern vicinity in normal and abnormal conditions, translation by U. Radok. Coop. Inst. Res. Environ. Sciences. University of Colorado and NOAA. Boulder, Colorado.

Schweigger, E., 1945: La "legitima" corriente del Niño, Bol. Comp. Admin. Guano, 21, 255-296.

Shen, G. T., E. A. Boyle and D. W. Lea. 1987: Cadmium in corals as a tracer of historical upwelling and industrial fallout, Nature, 328. 794-796.

Thompson, L. G., E. Moseley-Thompson and B. Morales-Amao, 1984: El Niño-Southern Oscillation events recorded in the stratigraphy of the tropical Quelccava Ice Cap. Peru, Science. 226. 50-53.

Zebiak.S. E. and M. A. Cane. 1987: A model El NiñoSouthern Oscillation Mon. Hea. Rev , 115.22622278 . 